\title{
XIV International Conference "Spectroscopy of Coordination Compounds" (September 24-30, 2017, Tuapse)
}

The XIV International Conference "Spectroscopy of Coordination Compounds" will be held on September 24-30, 2017, in Tuapse, Russian Federation.

\section{Conference Organizers}

N. S. Kurnakov Institute of General and Inorganic Chemistry, Russian Academy of Sciences Kuban State University (KubSU)

\section{Organizing Committee}

Chairman

Deputy Chairman Academic Secretary

B. I. Kharisov

G. Jonusauskas

J. Poler

V. P. Ananikov, Corresponding member (RAS)

V. K. Bel'skii

V. A. Varnek

V. K. Voronov

V. V. Dotsenko

G. A. Dushenko

I. L. Eremenko, Academician (RAS)

T. V. Kostyrina
V. T. Panyushkin (KubSU, Krasnodar)

N. N. Bukov (KubSU, Krasnodar)

F. A. Kolokolov (KubSU, Krasnodar)
V. V. Minin

V. I. Minkin, Academician (RAS)

A. G. Mirochnik

I. E. Mikhailov

V. M. Novotortsev, Academician (RAS)

A. I. Oflidi

O. A. Raitman

N. M. Sergeev

A. A. Sidorov

M. E. Sokolov

V. I. Chizhik

\section{Program Committee}

$\begin{array}{ll}\text { G. Jonusauskas } & \text { I. E. Mikhailov } \\ \text { N. N. Bukov } & \text { V. T. Panyushkin } \\ \text { S. V. Krivovichev } & \text { O. A. Raitman } \\ \text { V. V. Dotsenko } & \text { N. M. Sergeev } \\ \text { G. A. Dushenko } & \text { M. E. Sokolov } \\ \text { F. A. Kolokolov } & \text { V. I. Chizhik } \\ \text { V. V. Minin } & \end{array}$

Topics of the Conference

- NMR spectroscopy of coordination compounds;

- ESR spectroscopy of coordination compounds;

- Synthesis and spectral properties of complex compounds;

- Spectroscopic methods for investigation of supra- and nanosystems;

- Luminescence of coordination compounds and materials based on them;

- Optical spectroscopy methods in coordination chemistry;

- Practical applications of coordination compounds;

- Photochemistry of coordination compounds;

- Quantum chemistry of coordination compounds.

The scientific program of the conference includes plenary lectures, oral reports, a poster session, and workshop for young scientists "Modern Physicochemical Methods in Coordination Chemistry".

Contacts:

Fedor Aleksandrovich Kolokolov, Academic Secretary of the Conference.

Phone.: +7 (861) 219 9574, +7 (918) 440 2630; E-mail: spex.complex@mail.ru

\section{http://spec-complex.kubsu.ru/index.html}

